\title{
NOTAS SOBRE EL CONCEPTO DE IDEOLOGIA Y LA TRANSFORMACION DE LA ESCUELA*
}

\author{
José Fernando Garcz'a**
}

Las críticas efectuadas a la llamada teoría crítico-reproductivista de la educación formal, en sus distintas versiones, han puesto de manifiesto las dificultades de esa teoría para explicar la complejidad de la realidad escolar. Se ha señalado con razón que no deja espacio para las contradicciones y conflictos, poniendo énfasis exclusivamente en su eficacia como medio de imposición ideológica ${ }^{223}$. No obstante estas y otras pertinentes observaciones sobre los límites de la teoría reproductivista de la educación, no se ha formulado una teoría alternativa. En ese sentido es ejemplar el trabajo de D. Saviani ${ }^{224}$ que constituyendo un excelente análisis de las dificultades que afrontan las distintas teorías de la escuela, termina reconociendo lo poco que se ha avanzado en la construcción de una concepción que supere la disyuntiva ilusión (que caracteriza a las teorías no críticas) —impotencia (derivada de las teorías crítico-reproductivistas).

Pienso que los obstáculos para construir una teoría de la escuela que escape a las limitaciones del reproductivismo, se relacionan —al menos en parte - con el hecho de que la crítica propiamente tal a dicha teoría no ha sido llevada a cabo.

Entiendo que la crítica no solamente debe mostrar los aspectos en que una teoría es desmentida por la realidad, sino también identificar los conceptos (o falta de conceptos) que se encuentran en el origen de esa inadecuación. Si esta tarea crítica no es cumplida, se corre el riesgo sea de abandonar la teoría como un todo, incluyendo conceptos que conservan poder explicativo, o insistir —en otro contexto- estérilmente en aquellos que originan las dificultades.

El propósito de estas notas es mostrar, en primer lugar, que las limitaciones de la teoría reproductivista de la educación se originan fundamentalmente en el concepto de ideología como mera ilusión, mistificación o falsa conciencia socialmente necesaria; en segundo lugar, que el concepto de ideología que llamaré "dialéctico" permite explicar todas —o casi todas- las "anomalías" de la teoría reproductivista de la educación ${ }^{225}$, posibilitando

\footnotetext{
* Este trabajo forma parte de las actividades del autor en un proyecto de investigación sobre el trabajo docente que se lleva a cabo en FLACSO-Programa Buenos Aires con el apoyo del CIID de Canadá. Su contenido fue discutido en el seminario Interno del equipo de Investigación de dicho proyecto. Muchas de las ideas que aquí se exponen surgieron en conversaciones con Graciela Batallán o le pertenecen, pero no sería posible señalarlas en cada caso. Por supuesto que la responsabilidad es totalmente del autor.

** Licenciado en filosofía y sociólogo. Consultor del Programa Buenos Aires de la Facultad Latinoamericana de Ciencias Sociales y docente en la Universidad de Buenos Aires.

${ }^{223}$ Véase G. Snyders, Ecole, classes et lutte de classes. Une relecture critique de Baudelot, Establet, Bourdieu, Passeron et Ilich, París, PUF. 1976; D. Saviani, "Las teorías de la educación y el problema de la marginalidad en América Latina” en Revista Argentina de Educación No. 3, Buenos Aires, 1983; J. C.

Tedesco et al., El proyecto educativo autoritario, Argentina 1976-1982, FLACSO, Buenos Aires, 1983; J.C.

Tedesco, "El reproductivismo educativo y sectores populares en América Latina", en Revista Colombiana de Educación, Bogotá, 1983.

${ }^{224}$ D. Saviani, op. cit.

${ }^{225}$ Utilizó el término en el sentido en que lo usa T. S. Kuhn para indicar los resultados observacionales no esperados dentro de un paradigma científico, véase La estructura de las revoluciones científicas, México, F.C.E., 1971.
} 
también distinguir conceptos que en ésta aparecen confundidos o son difícilmente diferenciables; y finalmente, que en esa perspectiva la concepción de la escuela como "aparato ideológico de estado" adquiere una nueva significación teórica.

\section{DOS CONCEPTOS DE IDEOLOGIA}

La fuente inmediata del concepto de ideología como simple ilusión, mistificación o falsa conciencia es, sin duda, Louis Althusser ${ }^{226}$. Sin embargo, quien primero lo formuló en esos términos fue el Marx de la ideología alemana. Esto es hoy ampliamente reconocido, lo que me excusa de extenderme sobre ello, así como el hecho de que en la obra de Marx se puede encontrar otro concepto, al-que antes llamé concepto dialéctico de ideología ${ }^{227}$.

Lo que me interesa destacar ahora es que la ideología como falsa conciencia 1) se contrapone a la ciencia que es conocimiento de las relaciones reales de los individuos con sus condiciones de vida; 2) por tanto, "salirse" de ella implica remplazar ciertos contenidos en sí falsos por otros que tienen como característica ser verdaderos, científicos; 3) eso significa que los contenidos de la ciencia son ajenos a la vida común de los hombres, a sus valores, fines y utopías; 4) la ideología es expresión de los intereses de las clases dominantes, respondiendo la ciencia al de las clases subalternas, en tanto socava la integración de éstas a sus condiciones de vida.

Detengámonos en el punto 3). Hay por una parte relaciones reales que existen sin que necesariamente los individuos tengan conocimiento de ellas; por otra, relaciones ilusorias, ideológicas, a través de las cuales los individuos dan vida, realizan estas relaciones reales. Pero, podemos preguntar, ¿por qué los hombres hacen suyos valores, fines, utopías, mediante los cuales -y sin que ellos los sepan-viven las relaciones reales? La pregunta no tiene sentido en esa concepción de la ideología porque o bien los individuos no son sujetos sino "portadores" de relaciones sociales, o bien se. trata de pura "violencia simbólica". Mal puede plantearse entonces la cuestión sobre las razones prácticas de la vida social. Esto es coherente con el hecho de que "el fuera" de la ideología implique rechazar los contenidos de ella; nada hay en la ideología que sea rescatable y eso significa que la vida común de los hombres, sus aspiraciones, propósitos y valores son simple falsedad, error que contrasta con la claridad y transparencia de la ciencia.

Esto implica sostener que la ciencia conoce una objetividad social que existe independientemente de la subjetividad de los individuos. Sean cuales fueren las representaciones de éstos y las acciones que en ellas se originan, la objetividad social tienen un sentido determinado. Althusser lo expresa claramente en relación con la escala: "Pido perdón por esto a los maestros que, en condiciones espantosas, intentan volver contra la ideología, contra el sistema y contra las prácticas de que son prisioneros, las pocas armas que pueden hallar en la historia y el saber que ellos "enseñan". Son una especie de héroes. Pero no abundan..." ${ }^{228}$ No es casualidad, pues, que la lucha de clases, el papel que juega la subjetividad en las instituciones, haya sido introducida por Althusser

\footnotetext{
${ }^{226}$ L. Althusser, Ideología y aparatos Ideológicos de Estado, Nueva Visión, Buenos Aires, 1974.

${ }^{227}$ La Escueta de Frankfort ha rescatado este concepto de Ideología, haciéndolo uno de sus temas fundamentales de reflexión. Véase Th Adorno y M. Horkheimi,r. "La Ideología", en La Sociedad, Proteo, Buenos Aires, 1969, y M. Horkheimer, Crítica de la razón Instrumental, Taurus, Buenos Aires, 1973. Un muy buen análisis del concepto de Ideología de la Escuela de Frankfort puede encontrarse en el articulo "Ideología y crítica de la Ideología: Reflexiones en torno a una alternativa teórica" de R.A. Mayorga, en América Latina, Ideología y cultura, FLACSO, Colección 25 aniversario, San Jose, Costa Rica, 1982. Véase también A. Wellmer, Teoría crítica de la sociedad y positivismo, Ariel, Barcelona, 1969, pp. 101-120. ${ }^{228}$ Ideología y aparatos ideológicos de Estado, op. Cit. Pag. 45 
en un postscriptum a su trabajo Ideología y aparatos ideológicos de Estado ni que sea difícil conciliarla con la argumentación expuesta allí.

Si la objetividad social tiene un sentido independientemente de la subjetividad de los individuos y de las acciones que de allí se derivan, y la ciencia suministra el conocimiento de las leyes de esa objetividad, la relación entre ciencia y acción puede ser pensada solamente de una manera tecnológica. Los fines de la vida social estarian dados, inscriptos, por así decirlo, en la objetividad social y sería asunto de la ciencia conocerlos, la que suministraría también el conocimiento de los medios para alcanzarlos. De esta manera los fines de la vida en sociedad son sustituidos a la reflexión, puesto que perteneciendo al ámbito de la ciencia son indiscutibles.

Esta relación tecnológica con los fines es una de las consecuencias más gravosas de la concepción de la ideología como falsa conciencia. Consagra junto a la desvalorización de los contenidos de la vida común de los hombres, el privilegio de la figura del científico social que enseñaría a éstos cuáles son las relaciones reales con sus condiciones de vida, y el sentido de sus propias acciones.

Como se sabe, en el positivismo los valores y fines son sustraídos a la reflexión por la vía de considerarlos "irracionales", como decisiones que no se pueden justificar ni ser objeto de discusión. En el "racionalismo crítico" incluso la adhesión a la razón es una decisión irracional ${ }^{229}$. A mi modo de ver, no hace diferencia que los valores y fines de la vida en sociedad sean un dato de la subjetividad irracional o de la objetividad social. En este punto, la concepción de la ideología como falsa conciencia y el positivismo muestran afinidad $^{230}$.

Es posible oponer a este otro concepto de ideología que no pone énfasis exclusivamente en su falsedad y necesidad social. Según ese concepto, la ideología es falsa conciencia solamente en tanto hay algo que requiere ocultarse, un orden que no es aceptado o querido por los hombres, y si esto es así significa que los contenidos de la ideología, aquello que constituye la falsa conciencia, lo que oculta la realidad, son valores, aspiraciones, proyectos o utopías compartidas socialmente.

Para esta concepción ni los individuos ni la objetividad social pueden ser considerados como algo inmediato, un punto de partida que permita explicar el otro término. Los individuos no son una simple expresión de la objetividad social, con abstracción de su subjetividad, ni aquella puede ser reducida al sentido o significado que los individuos dan a sus acciones.

En esta no coextensividad de sociedad y significación habría que ubicar a la ideología. La significación que los hombres dan a su vida en sociedad no corresponde a lo que ésta es en realidad, y en ese sentido es falsa conciencia. Pero la falsedad no reside en los contenidos de esa conciencia, la significación que los hombres dan a sus acciones no son falsos. ¿Cómo podrían ser falsas las ideas de libertad, igualdad y justicia por ejemplo?

Más aún, la ideología sólo puede surgir en una sociedad en que la igualdad y la justicia son supuestos de la vida social. "En rigor — dicen Adorno y Horkheimer- cuando rigen

\footnotetext{
${ }^{229}$ Véase K. Popper, La Sociedad abierta y sus enemigos, Paidós, Buenos Aires, 1957, pp. 422-427. 8

230 "Gracias a su autocrítica, la razón tiene que reconocer la limitación de los dos conceptos antagónicos de razón; tiene que analizar el desarrollo del abismo entre ambos, tal como aparece eternizado por todas las doctrinas propensas a triunfar Ideológicamente sobre la antinomia filosófica en un mundo de antinomias" (M. Horkheimer, Crítica de la razón Instrumental • op. cit. pág. 183). 
relaciones de poder simples e inmediatas, no existen ideologías en el sentido estricto..."231. La ideología aparece desde el momento en que la sociedad mercantil desarrollada no corresponde a su propio concepto, en que la igualdad y la justicia que pretende realizar es negada en su existencia y ésta se ha vuelto problemática y necesitada de legitimidad. Pero por eso mismo, la ideología como legitimación de lo existente está constituida por aquellos contenidos que despiertan la adhesión racional de los hombres en tanto expresan "el buen orden

¿Dónde reside, entonces, la falsedad de la ideología? No en su contenido - como vimos- sino en su relación con lo existente, en la contradicción entre lo que la ideología pretende que lo existente es y lo que es efectivamente. Es falsa conciencia y oculta la realidad en tanto en ella lo existente aparece siendo lo que no es; aquello que oculta es, por así decirlo, el exceso de significado de la ideología, el hecho de trascender lo existente.

Es posible ver en este punto que la concepción de la ideología como falsa conciencia se fundamenta en la idea de conocimiento propia de las ciencias naturales. De acuerdo con esa concepción, la ideología correspondería a un conocimiento falso pero socialmente necesario. Ahora bien, en ciencias naturales la falsedad del conocimiento implica que éste debe ser desechado y remplazado por otro que se corresponda con su objeto. ¿Qué ocurre en ciencias sociales? La representación del intercambio de valores equivalentes en la relación capitalista es ideológica, por ejemplo. No corresponde a la realidad puesto que el capitalista compra la fuerza de trabajo y no el trabajo del obrero, y se asegura que el valor producido por la fuerza de trabajo sea superior al valor que por ella tiene que pagar ${ }^{232}$. Pero, ¿qué ocurre con la representación del intercambio de equivalentes? Es falsa, no cabe duda, en tanto no corresponde a la relación verdadera. Pero a diferencia de lo que ocurre en el conocimiento de las ciencias naturales, no es desechada como simple falsedad. Si entre ese pretendido conocimiento y la realidad no hay correspondencia, si la relación real es otra, es la realidad la que aparece como negativa, precaria o falta de sentido. En el ejemplo, la realidad es vista como explotación confrontada con el intercambio de equivalente ${ }^{233}$.

Aquí radica uno de los aspectos más importantes de esta concepción de ideología. Dice relación con la siguiente: lo que he llamado "el exceso de significado" de la ideología, al mismo tiempo que oculta y justifica lo existente, es también condición sine qua non de su crítica. La trascendencia de los contenidos ideológicos constituye potencialmente una idea regulativa de lo existente, una "utopía" en el sentido de que no está realizada pero permite pensarlo desde el punto de vista de su negatividad, como aquello que no es pero debería ser. De este modo, la crítica no es externa, no se trata de ideas sobre aquello que debería ser lo existente formuladas sin justificación al margen suyo, "utopías abstractas"; se trata, por el contrario, de un deber ser a través del cual lo existente mismo reclama legitimidad $^{234}$.

\footnotetext{
231 Th. Adorno y M. Horkheimer, La sociedad, op. cit., pag. 191

${ }^{232}$ Véase El Capital, Siglo XXI Argentina, volumen 1, Buenos Aires, 1975, pp. 215 y ss.

233 Esto muestra de una manera evidente que "lo económico"' no puede constituir un "nivel" o "instancia" de la sociedad, abstraído de los contenidos ideológicos.

${ }^{234} \mathrm{~N}$. Lechner parece entender que las utopías tienen un carácter externo a lo existente: "La necesidad originaria que obliga a la sociedad a referirse a un horizonte externo es la necesidad de hacerse inteligible y reconocible como sociedad por los individuos que la componen" (El consenso como estrategia y como utopía, Programa FLACSO, Santiago de Chile, pp. 31-32). Ciertamente hay utopías externas o abstractas pero ese no es el caso del contenido de las ideologías, Este es trascendente en cuanto va más allá de lo que existe pero al mismo tiempo expresa un significado inmanente a la realidad histórica y social, y sin el cual ésta no puede tener legitimidad ni existencia. Me parece que tanto las reflexiones de N. Lechner como 
Como dijera, "salirse" de la ideología en su concepción como falsa conciencia, implica negar los contenidos de ella y establecer una relación de conocimiento con la objetividad social. En la concepción dialéctica, en cambio, no "estar en la ideología", no solamente es compatible sino que exige afirmar los contenidos ideológicos, mostrando ahora su contraste con lo existente.

Se puede hablar de "objetivismo" en la concepción de la ideología como falsa conciencia en tanto en ella la transformación social está justificada por ser objetivamente necesaria. En la concepción dialéctica, la necesidad prdctica de la transformación se fundamenta en que la realidad niega valores y utopías compartidas socialmente pero sin los cuales ésta no puede tener existencia, al punto de pretender ser su realización. De este modo, la realidad social es, al menos virtualmente, contradictoria.

\section{EL VACIAMIENTO DEL CONCEPTO DE IDEOLOGIA}

Las dificultades que debe afrontar la concepción de la ideología como falsa conciencia sin más, ha llevado a ciertos autores a sostener que no es esa necesariamente una determinación de ella. Para el caso se pone el ejemplo de Hitler y el nazismo. Estos no se representaron falsamente sus reales intenciones ni pretendieron dar una justificación racional a sus actividades: "Hitler no ocultó nunca su designio de exterminar a los ju. díos"235.

Esta crítica en realidad comparte el mismo supuesto de la concepción a la que se opone: es ideología todo discurso no científico, y dado que el discurso nazi manifiestamente no lo es, debe ser considerado ideología. De acuerdo con esto puede pensarse en cierta ideología como un complejo discursivo que es expresión no mediada de lo existente. Pero en este caso, ¿puede hablarse de eficacia ideológica? Sin duda, el designio de exterminar a los judíos tuvo la adhesión de algunos pero despertó el rechazo en la mayoría de aquellos a quienes el terror nazi no podía alcanzar o la indiferencia temerosa de aquellos amenazados por éste. Pienso que si esa eficacia es "ideológica", el concepto de ideología ha perdido toda su eficacia teórica.

No todo discurso no científico es, pues, ideológico; el discurso nazi no lo es (o por lo menos no lo es el designio de exterminar a los judíos). Como vimos, no puede ser ideológico un discurso que no pretende ser expresión de valores socialmente compartidos, que no aspire a valer por lo que significa y se afirme en la amenaza o la presión. En ese sentido el contenido de la ideología es siempre verdadero, no lo falso y repudiable por los hombres. Pero por eso mismo la ideología es falsa conciencia en tanto un contenido verdadero aparece ocultando la falsedad de lo existente.

Los intentos de considerar unilateralmente la ideología como falsa conciencia o por el contrario como expresión directa de lo existente, conducen a dificultades insolubles o despojan al concepto de toda capacidad explicativa. Es sólo una paradoja aparente que ambas concepciones tengan los mismos resultados: pensar la ideología como algo impuesto, sea esta violencia simbólica, ilusión en la cual los individuos creen ser sujetos,

\footnotetext{
las de F. Hinkelammert (Crítica de la razón utópica D.El. Colección economía-teología, San José de Costa Rica, 1984) pierden fuerza al razonar abstractamente sobre las utopías sin establecer las diferencias del caso. Una crítica a la línea de argumentación seguida por N. Lechner puede encontrarse en C. Ruiz, "EI centenario de Marx en Chile", Alternatiuas No. 1, Santiago de Chile, septiembre de 1983

${ }_{235}^{23}$ N. Poulantzas, Estado, poder y socialismo, Siglo XXI, México, 1979, pág. 36; E. de Ippola, Ideología y discurso populista, Folios ediciones, México, 1982. pp. 87-88. 
o manifestación inmediata de intereses "por aberrantes y criminales que sean"236. En ninguno de estos casos la ideología se origina en la afirmación de contenidos dotados de legitimidad y que despiertan el consentimiento activo de los hombres.

Por otra parte, se ha postulado últimamente la identidad de lo discursivo y lo social, entendiendo por "discursivo" a la producción social de sentido. Se afirma que "resulta claro que si todo discurso tiene condiciones de producción específicas, estas condiciones -incluso cuando tienen caracteres de fijeza institucional- deben ser concebidos como otros discursos"237

Me parece irredarguible la afirmación de que es impensable "la posibilidad y la realidad de un social 'preconstituido' que escaparía o preexistiría lógicamente a la producción social de sentido: en suma, de un social "extradiscursivo “238, Sin embargo, no me parece valido inferir de allí que lo social sea coextensivo con lo discursivo. Lo social no puede, en efecto, tener existencia sin que los hombres tengan una representación de ello y sin que den un sentido a sus acciones en sociedad, sin la "producción social de sentido". Así entendido es cierto que no puede pensarse una realidad social "extradiscursiva". Pero esto no quiere decir que el sentido que los hombres den a su vida en sociedad agote la realidad de lo social; que las relaciones sociales supongan representaciones de esas relaciones no quiere decir que las representaciones correspondan a lo que las relaciones sociales son en realidad, a la objetividad social.

Es difícil ver qué utilidad teórica podría conservar el concepto de ideología en esa perspectiva. Si lo social se agota en la "producción social de sentido", si la representación que tienen los hombres de su vida en sociedad y lo que la sociedad es se identifican, ¿en qué sentido podría decirse que la ideología es falsa? Nuevamente se presentan las dificultades de afirmar de manera unilateral una de la ideología.

\section{Ideología y apertura de sentido de la escuela}

¿Qué ventajas ofrece lo que he llamado el concepto dialéctico de ideología para el análisis de la educación formal?

Digamos para comenzar que permite superar el funcionalismo implícito en la concepción reproductivista. Si la ideología es falsa conciencia sin más y la falsedad se origina en sus contenidos, sostener que la escuela es el medio principal de transmisión ideológica en la sociedad capitalista, implica que la enseñanza escolar no puede dejar de ser ideológica ni tener otra función que reproducir las relaciones vigentes. Las posibilidades de cambio en la escuela se limitarían a ser el resultado de transformaciones globales de la sociedad, ya que la ideología, siendo pura imposición, violencia simbólica, no contiene "ningún elemento de racionalidad con el cual la crítica pueda resarcirse" 239

Desde la perspectiva del concepto dialéctico de ideología, por el contrario, el sentido de la escuela no es algo dado de una vez y para siempre. Aun cuando transmita ideología, eso no implica que esté destinada a ser reproductora de las relaciones sociales.

\footnotetext{
${ }^{236}$ N. Poulantzas, op. cit. pág. 36. Igualmente E. Laclau: "Incluso el antisemitismo puede ser un rasgo ideológico característico de las más diversas clases" (Política e ideología en la teoría marxista. Capitalismo, fascismo, populismo. Siglo XXI editores, Madrid, 1978, pág. 110).

${ }^{237}$ E. Laclau, Ruptura populista y discurso, Comunicación presentada al coloquio sobre Texte et Institución, Universíté Québec á Montreal, Octubre de 1979.

${ }^{238}$ E. de Ipola. Ideología y discurso populista, op. cit. pág. 24.

${ }^{239}$ Th. Adorno y M. Horkheimer, La sociedad, op. cit. pág. 191. 
De acuerdo con lo que decíamos, los contenidos explícitos transmitidos por la escuela no son en sí mismos falsos. En ese sentido, es innegable que la escuela ha contribuido a transformar en sentido común el derecho a la igualdad y la justicia de todos los hombres. Este hecho explica la resistencia que el desarrollo de la educación popular encontró en las clases dominantes tradicionales, en particular en América Latina. La creación de ese sentido común era contradictorio, en efecto, con una modalidad de dominio asentado en la desigualdad formal. No era contradictorio en cambio - necesariamente, al menos-, con el dominio basado en la desigualdad material y sobre la base de la igualdad formal. De allí que muchas veces las clases subalternas contaran con el apoyo de los sectores dominantes no tradicionales en su lucha por la educación popular. Esos sectores han podido beneficiarse ideológicamente con la escuela, contrariamente a las clases dominantes tradicionales. El beneficio se basa en que la justicia y la igualdad formales son presentadas como la "única" justicia e igualdad posibles, como su cumplimiento.

Pero el sentido común sobre el derecho a la justicia e igualdad formales de todos los hombres que la escuela ha contribuido a crear es virtualmente una crítica al estado de cosas existente; basta mostrar que la desigualdad material impide aún la realización de la igualdad formal, que ésta no puede cumplirse en esas condiciones, para que los contenidos ideológicos transmitidos por la escuela se vuelvan críticas al orden existente.

El planteamiento de esta "apertura de sentido" de la escuela, que hace posible el concepto dialéctico de ideología, permite superar la disyuntiva ilusión-impotencia señalada por D. Saviani: la escuela en sí misma no es, como pretenden los liberales, una institución generadora de transformaciones, pero tampoco es necesariamente reproductora de las relaciones sociales vigentes, como lo plantean los "críticos". La escuela en abstracto puede ser una u otra cosa; qué sea en concreto dependerá de las luchas políticas, y en particular de aquellas que se dan dentro de la escuela misma.

Esto lleva a la pregunta sobre el sujeto de las transformaciones escolares. Pienso que tienen razón los que han rechazado las posiciones de quienes sostienen que toda transformación social tiene como sujeto a la clase obrera. Este es un supuesto de la teoría reproductívista en cuanto afirma implícitamente que los cambios en la escuela serán posibles cuando la relación social fundamental que liga a capitalistas y obreros sea abolida. De la misma manera, está implícita una visión de la revolución como un comienzo absoluto de las transformaciones. Evidentemente, es una representación simplista y errónea de la sociedad la reducción de toda forma de dominio o lucha a la relación capitalista-obrero, con abstracción de su especificidad, así como sostener que hay un momento fundacional de las transformaciones. Pensar, por el contrario, que la transformación social es más bien un resultado que implica luchar por la hegemonía en lugares específicos de la sociedad civil, plantea el problema de los sujetos de esas luchas.

\section{¿Cuál es, pues, el sujeto capaz de llevar a cabo las transformaciones de la escuela?}

Entre los agentes de la relación escolar son los docentes quienes poseen las condiciones objetivas que les permitirían eventualmente llegar a ser sujetos de las transformaciones de la escuela. En relación con esto hay que decir, en primer lugar, que las condiciones objetivas no son condiciones suficientes para la constitución de sujetos sociales, que no hay sujetos sociales "preconstituidos" por dichas condiciones. Si los docentes llegan o no a ser un sujeto social es algo totalmente contingente, de ninguna manera una determinación objetiva. En la constitución de los sujetos sociales hay una dimensión de sentido insoslayable y ésta no se encuentra dada en las determinaciones 
objetivas. Esto no quiere decir, sin embargo, que no haya determinaciones objetivas en absoluto ni que la constitución de sujetos sociales no tenga condiciones necesarias.

En el caso de los docentes esas condiciones necesarias las constituyen su permanencia y compromiso con el sistema educativo - contrariamente a lo que ocurre con los otros agentes de la relación escolar, alumnos y padres-, y fundamentalmente las condiciones de trabajo que tienen que afrontar. El trabajo del docente puede ser caracterizado por la subalternidad jerárquica dentro de una institución estatal (pública o privada), y éste junto a la calificación implica una ideología de la función escolar sin la cual no es posible de llevar a cabo. Ese "deber ser" les adscribe fuertemente una normativa de la que son portadores. Ese hecho es determinante: significa que los docentes poseen unidad e identidad mediante un complejo de significaciones compartidas, pero además que ese carácter ideológico los hace sufrir fuertes contradicciones en el ejercicio de su trabajo. En efecto, la fuerte carga normativa, inseparable del trabajo docente, implica que la contradicción entre esa normativa y la realidad cotidiana se manifieste de múltiples maneras, aunque no siempre explícitamente ${ }^{240}$.

¿Cuáles son las relaciones sociales específicas de la escuela y en qué sentido pueden ser transformadas? Aquí sólo es posible dejar enunciado el problema de manera muy general. La relación fundamental de la escuela es la relación docente-alumno y ésta es una relación asimétrica en tanto uno de sus agentes conduce la relación y por lo tanto tiene poder. Esto quiere decir que el poder del maestro sobre el alumno no emana de una fuente exterior a la relación misma y del cual éste sea representante. Como lo señala Foucault: "Más bien se debe hacer un análisis ascendente del poder, arrancar de los mecanismos infinitesimales, que tienen su propio trayecto, y ver después cómo estos mecanismos de poder han sido y todavía están investidos, colonizados, doblegados, transformados, desplazados, extendidos, etc., por mecanismos más generales y por formas de dominación global ${ }^{241}$ - En el caso de los docentes, su poder se halla "colonizado" por un sistema burocrático que a través de él se reproduce y reproduce las relaciones sociales vigentes.

De acuerdo con esto, se puede plantear que la transformación de la escuela implica que los docentes rescaten ese poder enajenado en el aparato burocrático, asumiéndose como sujetos en relación con el conocimiento y la enseñanza, es decir, como trabajadores intelectuales y no meramente como transmisores de un conocimiento que no contribuyen a crear ni del que se han apropiado ${ }^{242}$.

\section{Ideología, curriculum oculto y cultura}

Otra ventaja que ofrece el concepto dialéctico de ideología para el análisis de la escuela es que permite diferenciar determinaciones difícilmente distinguibles desde el punto de vista del concepto de ideología como falsa conciencia.

Es el caso de lo que se ha dado en llamar el "currículum oculto". Se denornina así a un "conjunto de mensajes implícitos en las formas de transmitir el curriculum explícito, en la organización misma de las actividades de enseñanza, y en las relaciones institucionales que sustentan el proceso escolar" ${ }^{243}$. Si la ideología es falsedad y violencia simbólica,

\footnotetext{
${ }^{240}$ Véase G. Batallán, Taller de educadores: Capacitación mediante la investigación de la práctica, FLACSO-Programa, Buenos Aires, 1983.

${ }^{241}$ M. Foucault, Microfísica del poder, Ediciones La Piqueta, Madrid, 1979, pp. 144-145.

${ }^{242}$ C. Btallán et. al, Taller de educadores. El mundo del niño y el aprendizaje escolar. Su incldencia en la reformulación del rol docente. Informe de Avance., FLACSO-Programa Buenos Aires, 1984.

${ }^{243}$ E. Rockwell, Dimensiones formativas de la escolarización primaria en México, DIE, México, 1981, pág. 1. Digitalizado por RED ACADEMICA
} 
¿dónde radica la diferencia entre el curriculum oculto y la ideología propiamente tal? Ambos compartirían la misma condición de ser simple imposición sin ningún contenido que pretenda valer por sí mismo. ¿Cómo explicar, por otra parte, que el curriculum oculto tenga ese carácter? En el contexto del concepto de ideología como falsa conciencia no parece posible una respuesta a estas cuestiones. Esto es válido también para aquellos autores que rechazando la teoría reproductivista de la educación, aceptan sin embargo implícitamente dicho concepto y consideran el curriculum oculto como "eficaz circuito de imposición ideológica"244.

De acuerdo con la concepción dialéctica de ideología, la relación entre ésta y el curriculum oculto es un caso específico de la relación entre ideología y objetividad social. Como dijimos, las relaciones sociales suponen representaciones de esas relaciones, lo que no quiere decir que correspondan a lo que ellas son realmente. Como de toda institución, hay una representación social de la escuela, expresada fundamentalmente en una normativa, la que pretende agotar su realidad. Con ello se oculta lo realmente existente, la escuela que existe independientemente de la representación que de ella se tenga. En ese sentido dicha representación es ideológica, falsa. Pero, sabemos, no es falsa en el sentido de que expresa el deber ser de la escuela, el buen orden escolar. Los contenidos del curriculum oculto, por el contrario, no poseen legitimidad alguna y solamente pueden tener una existencia oculta por la ideología. No bien los contenidos ideológicos pierden ese carácter y pasan a tener una función crítica, la condición de curriculum oculto queda de manifiesto, muestra ser lo inconfesable o inadmisible por una escuela comprometida con un deber ser.

Cuanto menos ideológica es la escuela, menos curriculum oculto requiere, corno puede verse en el caso de ciertos regímenes autoritarios, de "facto", en los que las necesidades de legitimidad son escasas. Allí "hay siempre una guiñada, un constante llamado a la fuerza bruta: prueba hacer uso de tu razón contra esta tesis y verás lo que sucede"245. Considérese, por ejemplo, la siguiente sugerencia que el programa entrega a los maestros de educación elemental bajo la dictadura militar en Chile: "Es de la mayor importancia que el profesor esté convencido profundamente que la persona es más o menos valiosa, o más o menos feliz por lo que es y no por lo que hace ni por lo que tiene. Sólo de este modo es posible orientar a muchos niños de nuestras escuelas hacia situaciones modestas, reales, evitando de esta manera crear expectativas brillantes pero falsas..."246. El discurso es expresión casi sin mediación de lo existente; no hay ocultamiento de la realidad ni la afirmación de un deber ser en la que ésta pretenda legitimarse. La realidad escolar se ha vuelto, para decirlo con palabras de Marcuse, "unidimensional", no contradictoria.

En contra de una opinión muy extendida, es posible afirmar que una sociedad, cuanto menos "ideologizada”, está más expuesta a la desintegración. La ideología como "la razón en su aspecto irrazonable", exige relacionar las luchas sociales con un sentido reconocido en instituciones y tradiciones. Pero sin ese momento "razonable anticipador" 247 ,no es posible la crítica, es decir, la confrontación en un horizonte de sentido que haga posible el consenso ${ }^{248}$ -

\footnotetext{
244 J.C. Tedesco, et al., El proyecto educativo autoritario, Argentina 1976-1982, op. cit. pág. 21.

245 Th. Adorno y M. Horkheimer, La sociedad, op. cit. pág. 192

${ }^{246}$ PIIE, Las transformaciones educacionales bajo el régimen militar, Santiago de Chile, 1984, pág. 273.

${ }^{247}$ A. Wellmer, Teortía crítica de la sociedad y positivismo, op. cit. pág. 112.

${ }^{248}$ Así, por ejemplo: "mientras menores sean las pretensiones de universalidad y absolutismo de las Ideologías predominantes en una sociedad determinada, mayores serán las posibilidades de reducir la Intensidad de lo. conflictos y maximizar los consensos". (H. Muñoz, "Ideologías y redemocratización. Apuntes para una discusión" en Alternativas No. 1, op. cit.). La conclusión de Muñoz es válida puesto que 
El concepto de ideología como falsa conciencia tampoco permite distinguir dicho concepto y el de cultura. No es difícil entender la razón de ello. Como vimos, el núcleo de esa teoría es la ciencia como reproducción de relaciones reales que existen independientemente de que se tenga o no conocimiento de ellas. Las representaciones de la vida común son pensadas como mero residuo; todo lo que no es ciencia es falso. El resultado es que los conceptos de ideología y cultura son indiferenciables, o lo que es lo mismo, el último desaparece en dicha teoría.

La distinción tampoco es clara en el pensamiento de Gramsci y por razones similares, aunque parezca paradójico. En efecto, para Gramsci la ideología es una "concepción del mundo que se manifiesta implícitamente en el arte, en el derecho, en la actividad económica, en todas las manifestaciones de la vida individual y colectiva"249. Una concepción del mundo se diferencia de otra por el grado de elaboración formal, la unidad y la coherencia que tenga, así como en la difusión que pueda alcanzar en la masa. Pero no puede decirse de una "concepción del mundo" que sea falsa en ningún sentido. Gramcsi señala que en la concepción popular del mundo, aunque dependiente de la concepción hegemónica, existe siempre un "buen sentido" que le permite captar su propia situación social y contradecir la ideología dominante. Expresa lo nuevo, la capacidad de ligarse a un presente en desarrollo, es "progresista". No obstante, el historicismo gramsciano al no hacer explícita la relación de la ideología con la falsedad tiene la misma consecuencia que la afirmación unilateral de aquella: la dificultad de distinguir ideología y cultura ${ }^{250}$.

Si la cultura está constituida por el universo de las significaciones, por las concepciones del mundo, habría que reparar en que no toda significación tiene la misma relación con lo real, o que una concepción del mundo incluye diferentes relaciones con la realidad. No puede decirse de toda significación que trascendiendo lo existente, sea justificación y ocultamiento y en ese sentido falsedad. Hay una variedad de maneras de ser, creencias, ritos, costumbres, etc., a los cuales no cabe llamarlos "verdaderos" ni "falsos", que no pretenden tener un contenido de conocimiento sobre lo que la realidad es, y mucho menos -cuando se muestra que la realidad no es como aparecía- que constituyan un "deber ser".

Me parece que puede ser fructífero reservar el nombre de ideología para las significaciones que poseen la condición de ser para los hombres algo racional y dotado de valor, y que oculta o justifica la realidad precisamente debido a esa condición.

De esta manera se hace posible distinguir tres conceptos que en los análisis sobre la escuela aparecen con frecuencia confundidos: cultura escolar, curriculum oculto e ideología.

parte de la concepción de "ideología contra ideología" en la que toda Ideología es relativa a una clase o grupo social, y por tanto, Inconmensurable, con lo que el resultado de su confrontación no puede ser el consenso sobre la base de un sentido compartido e Inmanente a la vida en sociedad sino la imposición de una sobre otras.

${ }^{249}$ A. Gramsci, El materialismo histórico y la filosofía de Benedetto Croce, Ediciones Nueva Visión. Buenos Aires, 1971, pág. 12.

${ }^{250}$ El reciente intento de J.L. Najenson de pensar la ideología como "síntesis de la cultura", supone que la ideología se define en relación a la ciencia: "Tendríamos, en cambio, ideologías 'más o menos científicas' y ciencia 'más o menos ideológica' en diversos momentos del proceso de conocimiento humano" (Cultura, ideología y democidio en América Latina, en América Latina: ideología y cultura, op. cit. pág. 57). 


\section{La escuela como unidad y diferencia}

Lo dicho hasta el momento es suficiente para entender que la teoría reproductivista de la educación formal tenga como resultado un conocimiento abstracto que afirma unilateralmente la unidad indiferenciada de la escuela. Sostener, en efecto, que la educación formal no puede dejar de cumplir la función de reproducir las relaciones sociales, cualesquiera que sean las condiciones concretas, lleva a poner énfasis en la unidad, pasando a ser irrelevantes las diferencias.

La perspectiva que abre el concepto dialéctico de ideología supone que la escuela, como toda realidad social, es unidad de la unidad y la diferencia. Como dijimos, la escuela constituye una objetividad social, un resultado que no corresponde a la voluntad ni a la representación de los individuos. No obstante, esto no quiere decir que esa objetividad social tenga una existencia independiente de la representación y acciones de los individuos. Que no haya coincidencia entre las representaciones que los individuos se hacen de la vida social y lo que ésta es, no quiere decir que la objetividad social existe mediante las representaciones y acciones de los individuos y así sea una entidad hipostasiada. La objetividad social existe una diferenciada, especificable en cada caso.

Esta perspectiva permite eludir el objetivismo y la abstracción de posturas como la representada por la teoría reproductivista de la educación. En esas posiciones la objetividad social no está mediada por las acciones y representaciones de los individuos sino que es concebida como una realidad inmediata y los individuos aparecen rígidamente determinados por ella. Incluso en sus versiones más radicales, la categoría misma de sujeto es una suerte de "astucia de las estructuras" que a través de esa relación imaginaria realiza sus determinaciones. Esto plantea, por una parte, el problema de cómo podría transformarse la objetividad social, puesto que eso supone la constitución de sujetos que al mismo tiempo aparecen como determinaciones de ella. Por otra parte, cómo pensar las diferencias en una perspectiva que negando la mediación de la objetividad social por los individuos, no puede dejar de afirmar la "impronta" directa y abstracta de lo social en ellos.

La perspectiva antes esbozada abre la posibilidad de pensar, en primer lugar, las diferencias de la escuela a través de la mediatización de la objetividad social por la cultura, esto es, por las distintas significaciones que adquiere, producto de la historia y de las tradiciones. La acción del Estado, por ejemplo, no es nunca una realidad que sea un reflejo uniforme en toda escuela. Los distintos contextos culturales diferencian su acción, resaltando por tanto, distintas realidades ${ }^{251}$.

Pero la diferencia de la escuela no se origina allí solamente. Como dijéramos, partiendo del concepto dialéctico de ideología, el sentido de la escuela no está dado, puede ser reproductora o no de las relaciones sociales y eso depende de las luchas sociales. Se abre así un amplio campo para conocer las diferencias, de acuerdo con situaciones específicas. Entre los extremos de una escuela reproductora y una escuela crítica, hay múltiples matices que solamente ci análisis empírico puede llegar a conocer.

Pero esta alusión a lo empírico no basta, sin embargo; es necesario tener el concepto de esas luchas y de la posible transformación de la escuela. Nos parece que la teoría que plantea que la escuela es un aparato ideológico ligado a otros aparatos de estado es adecuada, en el contexto del concepto dialéctico de ideología, para explicar su realidad.

\footnotetext{
${ }^{251}$ Véase J. Ezpeleta y E. Rockwell. La escuela: relato de un proceso de construcción inconcluso, DIE, México, 1983 
En efecto, se hace posible explicar así: 1) que la escuela pueda ser transformada, esto es, que pueda haber un cambio de hegemonía en su interior aún cuando no haya habido un cambio correspondiente en las relaciones sociales fundamentales de la sociedad. Sin embargo, una escuela crítica que esté en contradicción con esas relaciones será una conquista precaria si el movimiento que produjo las transformaciones no es capaz de articularse en un amplio movimiento que ponga fin a las relaciones de poder dominantes; pero 2) inversamente, un cambio en las relaciones sociales fundamentales tampoco será suficiente por sí mismo para asegurar la transformación de la escuela. En este sentido la teoría reproductivista de la educación se equivoca doblemente al pensar, en primer lugar, que no es posible cambiar la escuela sino como reflejo de cambios en las relaciones sociales fundamentales de la sociedad, y luego, que dichos cambios bastan para transformarla.

De ahí que se pueda afirmar que las transformaciones escolares sólo serán posibles mediante la confluencia de cambios en las relaciones sociales fundamentales ${ }^{252}$ con aquellos específicos de la escuela.

\footnotetext{
${ }^{252} \mathrm{Me}$ he referido varias veces a "las relaciones sociales fundamentales de la sociedad". Con ello aludo a las relaciones capitalistas que son fundamentales en el sentido de que constituyen "la potencia social dominante" y que tiende a penetrar todas las relaciones, sin Implicar la reducción de éstas a aquella.
} 